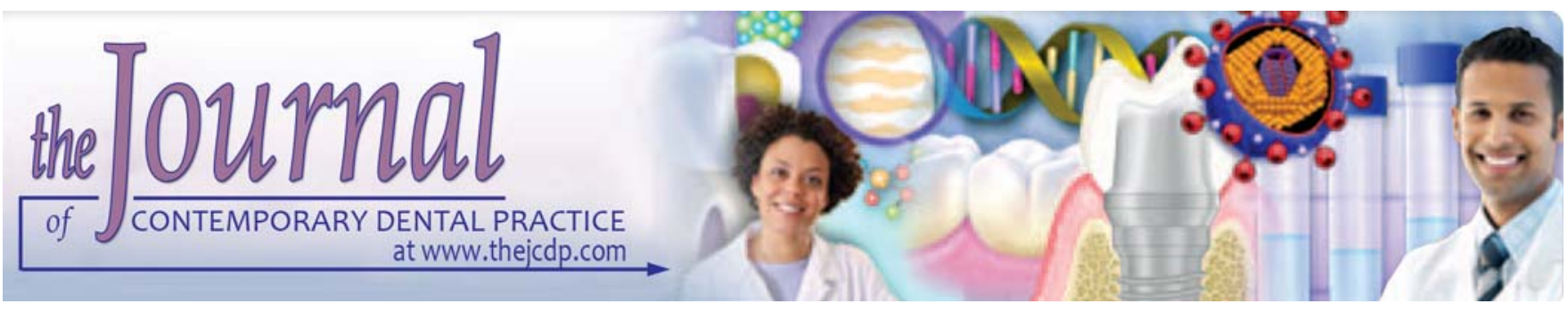

\title{
Efficacy of Microwaves and Chlorhexidine for Disinfection of Pacifiers and Toothbrushes: An in vitro Study
}

Jay Chamele, Chetan Bhat, Tanvi Saraf, Abhijeet Jadhav, Aumir Beg, Chetana Jagtap, Ritu Ubeja, Padmeshwari Patil

\begin{abstract}
Purpose: The purpose of this study was to evaluate, in vitro, the contamination of toothbrushes and pacifiers by Streptococcus mutans, and the efficacy of microwave and chlorhexidine for their disinfection.
\end{abstract}

Materials and methods: Sixty pacifiers and 60 toothbrushes were contaminated with $\mathrm{S}$. mutans and then divided into groups according to the disinfection protocol: Group 1-chlorhexidine solution; group 2-microwave sterilization; and group 3-sterile tap water. The devices were evaluated microbiologically after disinfection for the survival of $\mathrm{S}$. mutans colonies and were examined. The results were analyzed statistically by ANOVA and Turkey test.

Results: The results of both types of evaluation showed a large number of $\mathrm{S}$. mutans colonies after spraying with sterile tap water, and chlorhexidine spraying and microwaving were effective in eliminating colonies. Groups 1 and 2 were statistically similar to each other $(p>0.05)$ and differed significantly from group $3(p<0.05)$.

Conclusion: The $0.12 \%$ chlorhexidine solution spray and 7 minutes of microwave irradiation were almost equally effective for disinfection of pacifiers and toothbrushes.

Keywords: Chlorhexidine solution, Pacifier, Microwave, Toothbrush.

How to cite this article: Chamele J, Bhat $C$, Saraf $T$, J adhav A, Beg A, J agtap C, Ubeja R, Patil P. Efficacy of Microwaves and $C$ hlorhexidine for Disinfection of $P$ acifiers and Toothbrushes: An in vitro Study. J Contemp Dent Pract 2012;13(5):690-694.

\section{Source of support: Nil}

Conflict of interest: None declared

\section{INTRODUCTION}

Toothbrushes are free from microorganisms after the manufacturing process. ${ }^{1,2}$ They can, how ever, be contaminated after only one toothbrushing during 30 seconds to 4 minutes, ${ }^{3,4}$ by different types of bacteria, ${ }^{2,5}$ viruses $^{6,7}$ and fungi $i^{8,9}$ present in the oral cavity or the environment. ${ }^{10} \mathrm{As}$ public health policies emphasize the concepts of prevention and biosecurity, it is important to disseminate the idea that the toothbrushes should be stored, disinfected and replaced properly. There are, however, few studies that have evaluated toothbrush contamination and disinfection methods. $2,9,11-13$

Similarly, some authors ${ }^{14,15}$ have demonstrated that because the silicone or latex pacifiers are in permanent contact with saliva and the oral microflora, they constitute a site for the growth of microorganisms. The literature al so emphasizes that the use of pacifiers is associated with the occurrence of otitis media, ${ }_{16}^{16}$ dental caries ${ }^{17}$ and intestinal parasites as protozoan cysts and helminths eggs or larva. ${ }^{15}$ Indeed, these pacifiers can be considered a vehicle of contamination and microbial transmission in children and disabled patients.

While studies related to the contamination of pacifiers can be found in the literature, there are no studies referring to the use of disinfection methods to el iminate contamination by oral microorganisms. From a social point of view, these methods of disinfection should be effective, simple and inexpensive.

Some studies have suggested the importance of the disinfection of toothbrushes to reduce the number of microorganisms present on the bristles using UV radiation, ${ }^{13}$ electrolyzed water ${ }^{18}$ and chemical agents, such as listerine, plax, cepacol ${ }^{10}$ and chlorhexidine. ${ }^{12,19} \mathrm{~A}$ Ithough there are a few antimicrobial agents that could be used for disinfection, chlorhexidine is still considered the 'gold standard'.

Recently, several studies have evaluated microwave efficacy for the disinfection of dental devices and materials, such as prosthesis, ${ }^{20}$ acrylic resins ${ }^{21}$ and composites. ${ }^{22}$ Microwave irradiation is claimed to be a simple, effective and inexpensive disinfection method. 
Efficacy of Microwaves and Chlorhexidine for Disinfection of Pacifiers and Toothbrushes: An in vitro Study

The purpose of the present study was to evaluate, in vitro, the contamination of toothbrushes and pacifiers by Streptococcus mutans and the efficacy of microwave and chlorhexidine spray on their disinfection.

\section{MATERIALS AND METHODS}

Sixty silicone pacifiers ( $\mathrm{K}$ uka Baby) and 60 toothbrushes (Johnson Jr, Johnson and Johnson) were used from their original packages and soaked in a suspension of $S$. mutans (M TCC 890) at $39 \times 10^{6} \mathrm{CFU} / \mathrm{ml}$ for 5 minutes.

After exposure to $\mathrm{S}$. mutans, the pacifiers and toothbrushes were randomly divided to three groups of 20 specimens each, according to the following protocols described: G roup 1 -spraying four times with $0.12 \%$ chlorhexidine solution (Periogard, Colgate/Palmolive); group 2- disinfection in a microwave oven adjusted to potency level 7 (corresponding to $70 \%$ of full power) for 7 minutes and group 3-spraying four times with sterile tap water.

The microwave parameters used for disinfection of toothbrushes were established based on the results of a pilot study in which different potencies and periods of exposure to microwaves were evaluated. In the pilot study, 9 pacifiers were contaminated by a known $\mathrm{S}$. mutans concentration before exposure to microwave cycles of 7, 8 and 9 minutes. Two microwave potencies were compared (7 and 10). The best results for preventing the growth of microorganisms were obtained with 7 minutes of exposure to microwaves at potency level $7 .{ }^{31}$

The toothbrushes and pacifiers were transferred from the $S$. mutans solution to empty sterile glass containers (10 specimens per container) and exposed to microwave radiation for 7 minutes at potency 7 in a microwave oven. The containers were kept or arranged at a distance to avoid contact among them, and the toothbrush bristles and silicone pacifiers were placed in a vertical position (Fig. 1).

A fter treatment, the toothbrushes and pacifiers were transferred to flasks containing $\mathrm{B} \mathrm{HI}$ medium and incubated overnight at $37^{\circ} \mathrm{C}$ at $120 \mathrm{rpm}$. This was followed by plating the medium on brain heart infusion ( $\mathrm{BHI}$ ) agar plates for CFU measurement.

\section{Microbiological Analysis}

Streptococcus mutans (M TCC 890) was obtained from M icrobial Type Culture Collection and Gene Bank, Institute of M icrobial Technology, Chandigarh, India. The strain was maintained on $\mathrm{BHI}$ medium agar slants (composition per liter: BHI $10 \mathrm{gm}$, glucose $20 \mathrm{gm}$, tryptone $20 \mathrm{gm}$, yeast extract $20 \mathrm{gm}$, agar $15 \mathrm{gm}, \mathrm{pH} 7.2 \pm 0.2$ ). The culture was stored at $40^{\circ} \mathrm{C}$ and subcutured before use.
After 4 hours, the toothbrushes of each group were individually and vertically placed into $25 \times 150 \mathrm{~mm}$ test tubes containing $50 \mathrm{ml}$, MRS medium for 24 hours at $37{ }^{\circ} \mathrm{C} .{ }^{23}$ Each pacifier was individually placed in B orel tubes containing $50 \mathrm{ml}$ M RS medium and incubated in the same way as the toothbrushes. Evaluations of the surfaces for the presence of bacteria were made after incubation. A t each time, the toothbrushes and pacifiers were withdrawn, rinsed in the broth, and gently shaken to remove planktonic microbiota, leaving sessile bacteria adhered as 'spike' or 'mushroom-like' colonies. The toothbrush bristles and silicone pacifier surfaces were carefully analyzed on all sides, and sessile $S$. mutans colonies, based on colony morphology, were counted under aseptic conditions with a stereomicroscope (Nikon, Tokyo, J apan) with reflected light by a blinded examiner. The microbiological results were analyzed statistically with A NOVA and Turkey test.

\section{RESULTS}

In groups 1 , treated with chlorhexidine, the initial CFU of the culture was $39 \times 10^{6}$ and $32 \times 10^{6}$ for toothbrush and pacifiers respectively. A fter treating, it got reduced to 1 and 1 for toothbrush and pacifiers respectively (see Fig. 1).

In the groups 2 treated with microwave, the initial CFU of the culture for toothbrush and pacifiers was $39 \times 10^{6}$ and $32 \times 10^{6}$ respectively. After treatment it got reduced to 6 and 0 respectively (see Fig. 1).

In groups 3 that was treated with tap water, the initial CFU of the culture was $39 \times 10^{6}$ and $32 \times 10^{6}$ for toothbrush and pacifiers respectively. A fter treating it got reduced to 31 and 24 for toothbrush and pacifiers respectively. When $0.12 \%$ chlorhexidine spray and microwave were used (groups 1 and 2), colonies were absent in 100\% of the cases.

Groups 1 and 2 were statistically similar to each other $(p>0.05)$ and differed significantly from group $3(p<0.05)$ (Fig. 2).

\section{DISCUSSION}

In the present in vitro study, there was $S$. mutans contamination on $100 \%$ of group 3 toothbrushes, which were sprayed with sterile water. This result shows that the methodology is correct and can be used as a control in in vitro tests to evaluate the efficacy of different disinfection protocols (physical and chemical) before the in vivo evaluations. The present study's findings are similar to those of in vivo studies by M otzfeld et al, ${ }^{24} \mathrm{~N}$ el son Filho et al, ${ }^{12,25}$ and Quirynen et al, ${ }^{11}$ which described an intensive contamination by $S$. mutans on adult's and children's toothbrushes after use. 

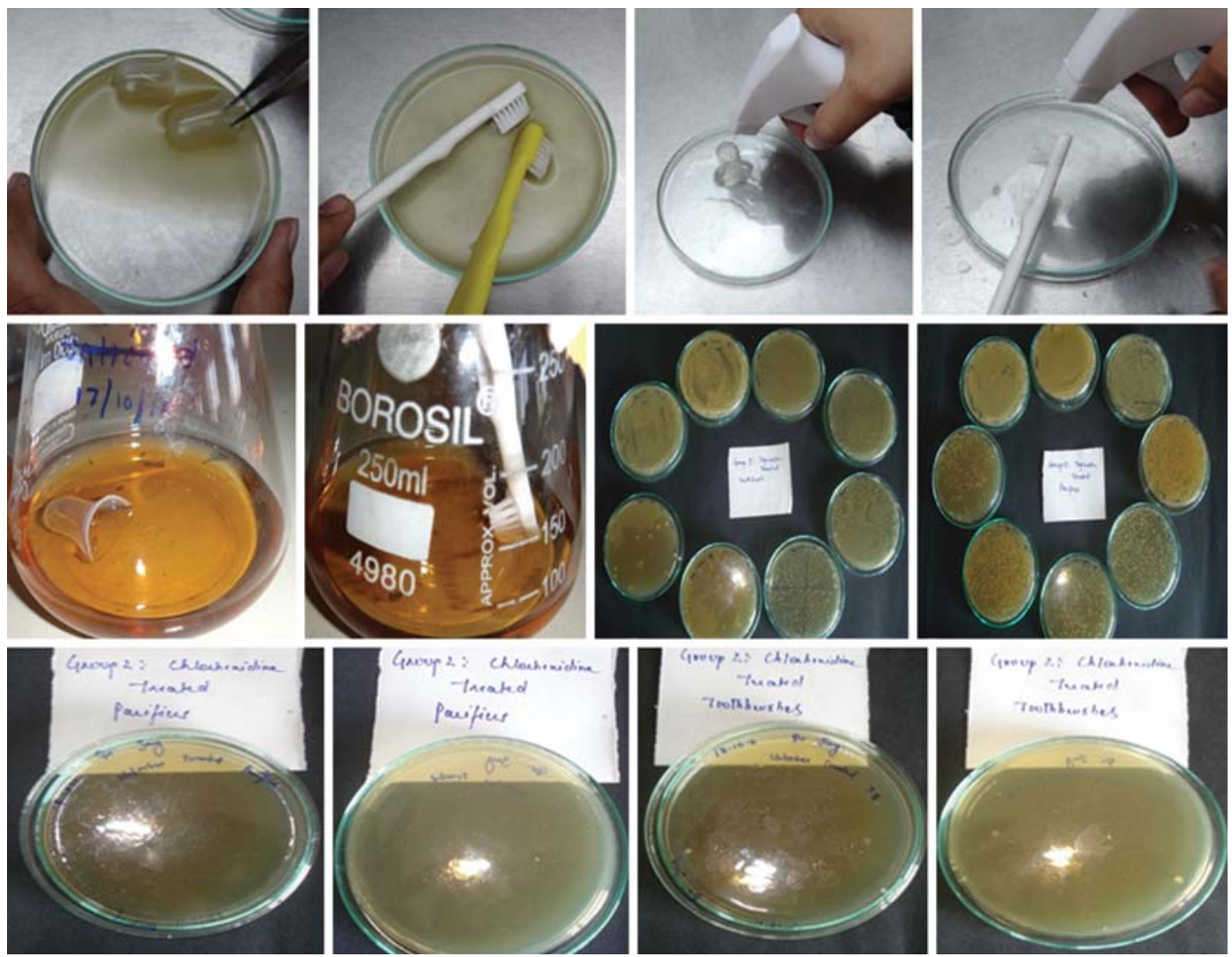

Fig. 1: The CFU count and disinfection of pacifiers and toothbrushes with chlorhexidine

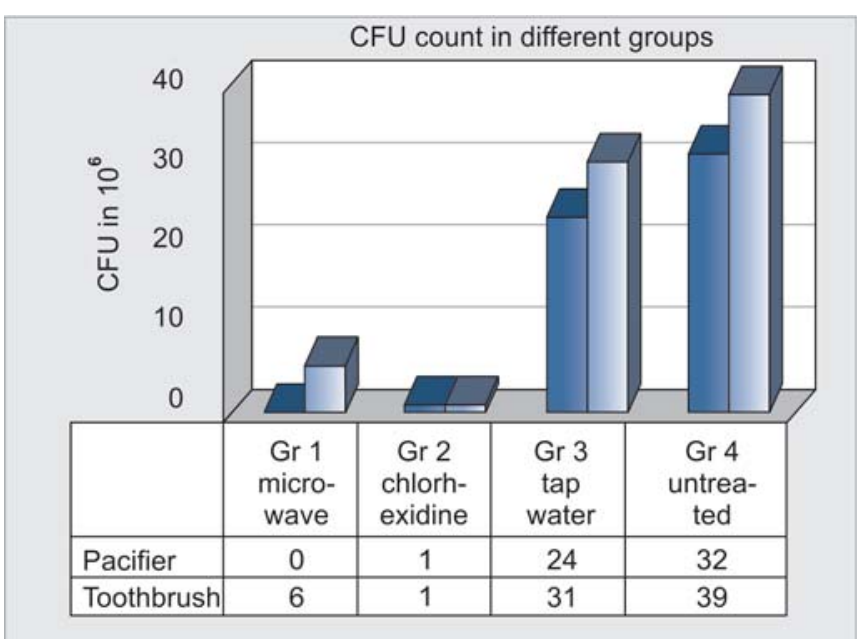

Fig. 2: The CFU of the culture for toothbrush and pacifiers

Several studies have suggested the importance of disinfection in reducing the number of microorganisms on toothbrush bristles. In the present study, the $0.12 \%$ chlorhexidine spray showed 100\% efficacy for toothbrush disinfection, eliminating all colonies in this group. These results agree with $\mathrm{N}$ elson-Filho et $\mathrm{al}^{2,12}$ and Saravia et al, ${ }^{2}$ who observed absence of $\mathrm{S}$. mutans growth in toothbrushes after the use of a $0.12 \%$ chlorhexidine solution. We agree with M oshrefi ${ }^{26}$ in that chlorhexidine is the 'gold standard' antimicrobial, compared to other agents used for dental biofilm control.
Although, the microwave efficacy has been evaluated only in prothèses, ${ }^{20}$ acrylic resins ${ }^{21}$ and composites, ${ }^{22}$ in the present study this method was also effective in eliminating microorganisms from toothbrushes. It is important to highlight that in the present study efficacy was evaluated at a single power parameter (potency level, $7-70 \%$ from 1,100 watts), and the results could not be generalized to other microwaves with different parameters. Dental practices must take this into account when they will choose power levels and microwave models.

Pacifier nipples, made of silicone or latex, are in permanent contact with saliva and, therefore, oral microflora. For this reason, their surface is a preferential site for the growth of biofilms. ${ }^{27,28}$ As biofilm micro-organisms are components of the oral microflora, it may be assumed that they also attach to pacifier nipple material. ${ }^{15} \mathrm{~A}$ few authors have searched for specific microbial species on pacifiers. Pedroso and Siqueira ${ }^{29}$ demonstrated that pacifiers were an important source of infection by intestinal parasites. M attos$G$ raner et $a^{28}$ found a relationship between the use of pacifier and yeast proliferation in the oral cavity. According to the A merican A cademy of Pediatrics, gastrointestinal infections and oral colonization with Candida albicans are more common among pacifier users. Comina et al ${ }^{15}$ observed $80 \%$ of biofilm colonization on pacifier nipples and stated that the pacifiers can be seen as potential reservoirs of pathogens. 
In the present study, $75 \%$ of group 3 pacifiers were contaminated with S. mutans, which is the primary etiologic agent of dental caries. A ccording to Ollila et al ${ }^{30}$ prolonged pacifier sucking is a possible risk factor for dental caries in children. M oreover, microorganisms from the environment are able to adhere to pacifiers, as children often drop their pacifiers on the floor and do not take good care of them. This contact with a wide range of microbial species might boost biofilm formation on the surface of pacifier nipples. Therefore, pacifiers can be contaminated by $\mathrm{S}$. mutans after use and should be disinfected.

We agree with Comina et al ${ }^{15}$ in that a correct disinfection of pacifiers is important to limit contamination. Hospital nurseries give strict instructions for the disinfection and sterilization of feeding bottles, but they do not give similar instructions for pacifiers. Strict rules of hygiene and an efficient antibiofilm cleaning protocol should be established to answer the worries of parents concerning the safety of pacifiers. Regarding this issue, we observed that simply cleaning pacifiers with water (group 3 ) was not able to control the microbial contamination.

On the other hand, the use of chlorhexidine solution or microwaves as disinfections methods resulted in 100\% elimination of S. mutans. It was not possible to compare our results to the literature, however, because there are few papers addressing microbial contamination on pacifiers. Similarly, there is no paper related to pacifier disinfection with $0.12 \%$ chlorhexidine or microw aving. Further, in vitro studies and clinical trials are needed at other research levels to evaluate disinfection methods with different types of microorganisms.

\section{CONCLUSION}

1. When $0.12 \%$ chlorhexidine spray and microwave were used, colonies were absent in $100 \%$ of the cases.

2. Chlorhexidine solution spray $(0.12 \%)$ and 7 minutes of microwave irradiation were effective for disinfection of pacifiers and toothbrushes.

\section{REFERENCES}

1. Carvajal E, Gálvez P, Majlis G, Oyarziin A. Presencia de microrganismos em cepillos dental es utilizados em higiene oral habitual. Rev Dent Chile 1995;85:25-28.

2. Saravia M E, N elson-Filho P, da Silva RA, Faria G, Rossi MA, Ito IY . V iability of Streptococcus mutans toothbrush bristles. J Dent Child 2008;75:29-32.

3. W arren DP, Goldschmidt M C, Thompson M B, A dler-Storthz K, $\mathrm{K}$ eene $\mathrm{HJ}$. The effects of toothpastes on the residual microbial contamination of toothbrushes. J A m Dent A ssoc 2001;132: 1241-45.

4. Nelson-Eilho P, Isper AR, A ssed S, Faria G, I to IY. Effect of triclosan dentifrice on toothbrush contamination. Pediatr D ent 2004;26:11-16.
5. M ehta A, Sequeira PS, B hat G. B acterial contamination and decontamination of toothbrushes after use. N Y State Dent J 2007; 73:20-22

6. Leroy V, Zarski JP. W hat is the status of hepatitis $C$ virus infection in France? Gastroenterol Clin Biol 1999;23:349-51.

7. Lock G, Dirscherl M, Obermeier $F$, et al. Hepatitis $C$ contamination of toothbrushes: M yth or reality. J V iral Hepat 2006;13:371-73.

8. B unetel $L, T$ ricot-D oleux $S, A$ gnani $G$, B onnaure-M al let $M$. In vitro evaluation of the retention of three species of pathogenic microorganisms by three different types of toothbrush. Oral Microbiol Immunol 2000;15:313-16.

9. Devine DA, Percival RS, Wood DJ, et al. Inhibition of biofilms associated with dentures and toothbrushes by tetrasodium EDTA . J A ppl Microbiol 2007;103:2516-24.

10. Caudry SD, K litorinos A, Chan EC. Contaminated toothbrushes and their disinfection. J Can Dent Assoc 1995;61:511-16.

11. Quirynen M, De Soete M, Pauwels M, Gizani S, van M eerbeek B, van Steenberghe D. Can toothpaste or a toothbrush with antibacterial tufts prevent toothbrush contamination? J Periodontol 2003;74:312-22.

12. Nelson-Filho P, Faria G, Silva RAB, Rossi MA, Ito IY Evaluation of the contamination and disinfection methods of toothbrushes used by 24-to-48-month-old children. J Dent C hild 2006;73:152-58.

13. B erger JR, Drukartz MJ, Tenenbaum M D. The efficacy of two UV toothbrush sanitization devices: A pilot study. N Y State Dent J 2008;74:50-52.

14. E rsin NK, Eronat N, Cogulu D, Uzel A, A ksit S. A ssociation of maternal-child characteristics as a factor in early childhood caries and salivary bacterial counts. J D ent Child 2006;73:105-11.

15. Comina $E, M$ arion $K$, R enaud FN, Dore J, B ergeron E, Freney J. Pacifiers: A microbial reservoir. N urs Health Sci 2006;8:216-23.

16. Rovers $M M, N$ umans $M E$, Langenbach $E$, Grobbee $D E$, V erheij TJ, Schilder A G. Is pacifier use a risk factor for acute otitis media? A dynamic cohort study. Fam Pract 2008;25: 233-36.

17. Vázquez-Nava $F, V$ ázquez $R E$, Saldi var $G A$, B eltrán $G F$, Almeida AV, V ázquez RC. Allergic rhinitis, feeding and oral habits, tooth-brushing and socioeconomic status: Effects on development of dental caries in primary dentition. Caries Res 2008;42:|4|-47.

18. Lee SH, Choi BK. A ntibacterial effect of electrolyzed water on oral bacteria. J Microbiol 2006;44:417-22.

19. A yegiil O, Elgin IE, Gulcin A, Nedim S. The efficacy of chlorhexidine spray vs mouthwash in the microbial contamination of child toothbrushes. J Dent Child 2007;74: 177-81.

20. Mima EG, Pavarina AC, Neppelenbroek KH, Vergani CE, Spolidorio DM , M achado A L. Effect of different exposure times on microwave irradiation on the disinfection of a hard chairside reline resin. J Prosthodont 2008;17:312-17.

21. Pero AC, Barbosa DB, Marra J, Ruvolo-Filho AC, Compagnoni $M A$. Influence of microwave polymerization method and thickness on porosity of acrylic resin. J Prosthodont 2008;17:125-29.

22. Sartori EA, Schmidt CB, W alber LF, Shinkai RS. Effect of microwave disinfection on denture base adaptation and resin surface roughness. B raz D ent J 2006;17:195-200.

23. Lessa FC, Enoki C, I to IY, Faria G, M atsumoto M A, NelsonFilho $P$. In vivo evaluation of the bacterial contamination and 
disinfection of acrylic base plates of removable orthodontic appliances. A m J Orthod Dentofacial Orthop 2007;131:e11-17.

24. M otzfeld R, Huerta J, A pip A, A raya E. Tipo y grado de contaminación por bacterias bucales y levaduras decepillos dentales con uso habitual. Rev Fac Odontol Univ Chile 1999; 17:9-14.

25. Nelson Filho P, M acari S, Faria G, A ssed S, I to IY . M icrobial contamination of toothbrushes and their decontamination. Pediatr Dent 2000;22:381-84.

26. M oshrefi A . Chlorhexidine. J W est Soc Periodontol Periodontal A bstr 2002;50:5-9.

27. Brook 1, G ober A E. Bacterial colonization of pacifiers of infants with acute otitis media. J Laryngol O tol 1997;111:614-15.

28. M attos-Graner RO, M oraes AB, Rontane RM P, Birman EG. Relation of oral yeast infection in B razilian infants and use of a pacifier. J Dent Child 2001;68:33-36.

29. Pedroso RS, Siqueira RV . A study on protozoan cysts, hel minth eggs and larvae in pacifiers. J Pediatr 1997;73:21-25.

30. Ollila $P, N$ iemela $M, M$ atti $U, L$ armas $M$. Prolonged pacifiersucking and use of a nursing bottle at night: Possible risk factors for dental caries in children. A cta Odontol Scand 1998;56: 233-37.

31. Nelson Filho P, A ssed S, Raquel S, Luciana S. Disinfection of pacifiers and toothbrushes. J Pediatric Dent 2011;33:10-13.

\section{ABOUT THE AUTHORS}

\section{Jay Chamele (Corresponding Author)}

Postgraduate Student, Department of Pedodontics and Preventive Dentistry, B harati V idyapeeth Dental College, Pune- 411043 $\mathrm{M}$ aharashtra, India, e-mail: jchamele@ gmail.com

\section{Chetan Bhat}

A ssociate Professor, Department of Pedodontics and Preventive Dentistry, B harati V idyapeeth Dental College, Pune, M aharashtra, India

\section{Tanvi Saraf}

Postgraduate Student, Department of Pedodontics and Preventive D entistry, B harati V idyapeeth D ental College, Pune, M aharashtra, India

\section{Abhijeet Jadhav}

Postgraduate Student, Department of Oral M edicine and Radiology B harati V idyapeeth D ental College, Pune, M aharashtra, India

\section{Aumir Beg}

Postgraduate Student, Department of Pedodontics and Preventive Dentistry, B harati V idyapeeth Dental College, Pune, M aharashtra, India

\section{Chetana Jagtap}

Postgraduate Student, Department of Pedodontics and Preventive Dentistry, B harati V idyapeeth D ental College, Pune, M aharashtra, India

\section{Ritu Ubeja}

Postgraduate Student, Department of Pedodontics and Preventive Dentistry, B harati V idyapeeth D ental College, Pune, M aharashtra, India

\section{Padmeshwari Patil}

Postgraduate Student, Department of Pedodontics and Preventive Dentistry, B harati V idyapeeth Dental College, Pune, M aharashtra, India 